\title{
ON PROGNOSTICS OF PSYCHODIAGNOSTIC METHOD CREATIVE FIELD
}

\author{
Diana B. Bogoyavlenskaya \\ Lomonosov Moscow State University \\ Moscow
}

\begin{abstract}
This paper reports on the results of the 40-year longitudinal studies based on the author's conception of creativity as generation of activity at one's own initiative and pursued by the method Creative Field, which has been developed by the author purposely to explore this particular phenomenon. The method allows dividing people with high abilities into those who attain proficiency and those who push the boundaries and move to the level of art even in science, which characterizes the higher forms of creativity. The universality of the method as a diagnostic instrument proves the possibility to identify creative abilities on samples of seemingly alternative professions: in exact sciences and in art. The validity of this method is confirmed by the absolute coincidence of the diagnostic findings and the life course of the subjects in the given samples. Moreover, the diagnostic findings in children of school age have been sustained for a period of over 40 years, which speaks for the apparent prognostics of the method.
\end{abstract}

Keywords: creativity, cognitive need, cognitive self-activity, motivation, stimulus, challenge, generation of activity.

The philosopher Hegel viewed cognition as movement of thought from the singular through the particular to the universal. The science theorist Popper described development of scientific knowledge from the solution of a local problem to the discovery of regularities, i.e. principles, and to the theory, which proves them on the universal level. And finally, the conceptualization of reality that similarly moves "in the scale of the socio-cultural significance of the world... [and] extends the field of the reality which possesses the vital human sense" (Ivanov, 1977, p. 244), is embodied in art. K. Paustovsky showed by means of literature that firstly a thought finds the connection between a natural phenomenon, the surf, and a fragment of culture, hexameter, as its reflection (Homer composed his verses listening to the rhythm of breaking waves), and thus 
the thought comes to the level of the particular. And then the thought achieves the universal level, finding this principle in the laws of the whole objective reality: the same rhythm is repeated in the shape of the islands. "It resembles the titanic hexameter that covered the sea with the solid strophe - from Hellas to the coast of Asia Minor" (Paystovsky).

One principle is obvious in all of these different realms. It is also reflected in our understanding of the nature of creative abilities. The movement of the thought that we could trace in our subjects, who were capable to generate activity at their own initiative (Bogoyavlenskaya, 2002), is not a result "in vitro". The movement from the local vision through the particular to the universal is the principle of cognition that ensures the higher forms of creativity in any activity.

I remind you that I regard the phenomenon of the generation of activity at one's own initiative as the manifestation of the cognitive self-activity. The phenomenon of the generation of activity is viewed in its turn as a 'unit of analysis' of creativity which integrates in itself cognitive and affective spheres of personality (Bogoyavlenskaya, 2008). In accordance with this definition of creativity I have developed the psychodiagnostic method of Creative Field (Ibid.) ${ }^{1}$.

The method not only makes it possible to identify creative children and adults, but it is also an expert method of differentiation between genuine giftedness and its distinct features, i.e. a high level of development of general and specific abilities and the availability of the necessary competencies.

It should be pointed out again that the given method enabled me to distinguish experimentally and based on the single objective criterion

${ }^{1}$ Its development required the construction of a new model. As opposed to the model of the problem situation, in which the thought moves somewhat in one dimension, it should have volume in order to reveal another dimension for tracing the thread of the thought beyond the limits of solution of the initial problem. The system of the uniform tasks with some range of common regularities suits this purpose. Such system of tasks provides the construction of the two-layer model of activity. The first one, the surface layer, is the prescribed activity of solving the local problems; and the second one is the deep layer, masked by the 'surface' layer and unobvious to the subject, it is the activity of revealing the implicit regularities, contained in the whole system of the tasks, which is unnecessary for their solving. The method may be implemented on various materials, but it should correspond to the 3 principles: absence of the inner or outer evaluative stimulus, absence of the ceiling limit in the whole system of activity, durability and recurrence of the experiment. 
the levels of realization of activity. They are: the stimulus-productive level - activity may be realized highly successfully, but it is always externally stimulated. On this level the highest manifestations reflect only the high level of development of abilities. The tasks are viewed as local. This is the analysis on the level of the singular.

The heuristic level - the person has acquired the activity, then develops it further at his or her initiative and moves over to the discovery of the new regularities. This is the analysis on the level of the particular.

The creative level - the discovered regularities are viewed by the person as a new emerging problem that needs to be proved, i.e., it should be theoretically grounded. This is the analysis on the level of the universal that enables one to find out the essence of the phenomenon, and hence gives one the possibility to predict qualitative leaps in its development.

Similarly to W. James, who extracted cognition in the strict sense of the word from the sphere of mental processes, our differentiation of the productive phenomenology enables us to extract creativity "in the strict sense of the word" from the realm of productive processes. In my opinion, creative abilities are manifested only when the subjects attain the heuristic and creative levels as they demonstrate the ability of an action that loses the form of answer. A product in any sphere of activity generated not only by the result of an effect of a definite stimulus, but also by a "challenge" in a broad sense is what I view as productive thinking. It does not mean that productive thinking is opposed to creative abilities. The fact is that productive thinking ensures our acquisition of activity and solving the formulated problems. But special personality features are required so we can initiate the development of this activity. According to F. Galton, we need such personal qualities that will "ensure the realization of mind" (Galton, 1865, p. 322).

Our theoretical position requires considering and detecting those life circumstances that influence the formation or the deformation of personality, as it directly affects the level of creative abilities. That is why we had planned to conduct a study of the genesis of creative abilities in the acmeological light. participants of the study were students of grades 8-10 in 1970-1971, who have now achieved the age of creative maturity (especially in the exact sciences). We have reliable data about the initial 
level of their creative abilities at a young age. Moreover, we can conduct a current psychodiagnostic study and analyse the results, which the subjects have achieved in their professional activity. Thus, it all creates the objective framework for the analysis of the role of key events of their lives in realization, development or regress of creative abilities.

The central task of the ongoing longitudinal study has been to analyze the role of the personality structure, its resilience to the influence of the external conditions; to find out, which personal orientations facilitate this or, alternatively, lead to the involution of creative personality; to understand the role of key life events in realization, development or regress of creative abilities. The research of the formation and the development of creative abilities simultaneously solves the problem of prognostics of the given method. The results obtained on this sample address the issues above.

Presently the experiment has been conducted with 38 participants of the initial school sample of 60 subjects, because by 2000,10 people emigrated and 12 could not take part in the experiment for various reasons.

The fact that the subjects largely retain the initial level, which had been formed in the youth, indicates the stability of this personality formation. However, some dynamics, both positive and negative, have been found.

Among the schoolgirls of the initial sample there was only one girl, who came to the heuristic level already at the beginning of the experiment. She demonstrated it again in 2002. At present she is a good scientist, she is successfully working on a topical issue in a think tank; her research is being funded by several international grants. The second girl, V.L., behaved inconsistently during the experiment as she suffered from anxiety, as well as many other girls in this school. When she was a university student she did her best to realize her ambition and is now fast on her way to the heuristic level. She is now a renowned medical researcher has made an important discovery in cardiology.

Negative dynamics is revealed in the case of some disease and a shift in values which were obviously shared by the subject during the school years but have never been personally appropriated. We observe this in R.M., who took a job in a bank and dismissed research. Another case is Sh.T., who gave up research and started work in the prosperous firm. It is not a mere chance that they have got a dominating consumer motiva- 
tion. Though, there is another person among the heurists whose motivation is not steady. Excellent intellectual ability and cognitive motivation enable him to stay on the heuristic level so far, though due to the recent political changes in the country he switched science to the current affairs journalism and then to political studies.

Remarkable is fact that the only person among those with the stimulus-productive level, P.Z., works in a think tank, and he has a lot of everyday personal problems and a very low level of aspirations. On the other hand, there is the former prefect of a municipality, who is currently the leader a political party in Moscow. But most subjects lecture in universities. By the way, only $1 / 6$ of the sample have got a $\mathrm{PhD}$. The dynamics of their career is very much related to the evolution of the country's economics. They started as post-graduates of universities of various levels and reputations, working as contract lecturers paid by the hour at the occasional faculties. Then, in the early 90s their research career was interrupted by the boom of the high-paid work in firms that shortly disappeared, in banks that went bankrupt and so forth. Eventually they returned to research as some universities started functioning not only on government money. Such universities need professionals with much expertise in modern economy rather than simply academics.

The typical representative of heurists, H.I., expressed it in a rather extravagant form. When I asked him why he had left school without honours, he was amazed at my forgetfulness: "I always had two marks: 'poor' and 'excellent'. 'Excellent' - when I felt interested, when there was something to think about. When choosing a university, I was thinking not of the future career, but of what would be more interesting for me. That was why I chose physics and technology. And now the same thing is important to me". H.I. conducted several important and valuable studies; he is enthusiastic about his theme and boyishly certain that he is simply satisfying his interest.

Half of the sample of heurists continues working in think tanks, at best winning bread for their families with international projects. $1 / 4$ of the sample work in universities and only $1 / 10$ are in firms. More than half of the sample have a post-doctoral degree "doktor nauk", and only $1 / 7$ (those who work in firms) do not have a PhD.

The life stories of S.L. and R.B. are typical of this sample. Both were the brightest students in Grade 8, but their paths diverged in years of 
transition from high school to university and further on to post-graduate schools. It was S.L.'s humble reaction to his academic achievement in Grade 10 that came as a total surprise for the experimenters rather than the fact that he demonstrated the best results in our tests

We kept an eye on Sasha L. up to the moment when he left school. As a pupil he was 'working' calmly and busily in the experiment, but during the third task he slowed down. It turned out that previously he had found some regularity and started to look for its proof. When he had solved his problem he gave the answer to the latest task and explained the delay by the necessity to prove the theorem. "We are taught like that. If I have found a new regularity, I should prove it before use", explained Sasha. It should that they were all taught like that, but it was just he who acquired it. When he saw the experimenter taking away the forms he asked: "What about the next ones?" - "The test is over; you have used up the potential of the material", the experimenter reassured him. The boy looked at the form in bewilderment: "Why give so many positions if one needed just to derive the theorem?" The experimenter explained that some people needed to solve many problems before that. Sasha was confused: "Is it possible?" He was merely puzzled; there was no sign of victorious joy or feeling of superiority.

The rare modesty of the bright student along with the brilliant move onto the highest level in the experiment made it natural for us to wait for some extraordinary results in the future. 5 years later we found Sasha as a post-graduate working on his $\mathrm{PhD}$ paper. He readily put his work aside to talk to us and when heard we were intent on conducting the new experiment he answered with a joke: "Now I am a theorist myself, so I manage my time the way I like". He came on the first appointed day. The experiment was based on a new method similar to the method Creative Field, and Sasha showed the same high level as 5 years ago.

Another student from the same class - Volodya K. - had a different type of personality. He was a handsome and talented teenager, and in the secondary school his character was not completely formed and was affected by everyone's admiration. In high school he was "overshadowed" by other children and the ambitious "leader" became egocentric, which incidentally prevented him from coming to the highest level. Every time he found a regularity in the experiment material he inquired: "What about the other participants?" 
What did he do after the school? He graduated from university, started his postgraduate studies. He didn't welcome our idea to conduct the experiment again: "I am busy with my research", declared he. "And besides, I am taking part in the chess tournament, so I don't have any time". But when he was told that all his former classmates were involved in it, he agreed: "However, you may come to my place". During the experiment it was clear the same question puzzled him: "Have you tested the others with the new method? What were the results?" Actually, Volodya's level significantly lowered in the second experiment.

We have received evidence that the experiment shows very well which subjects may ignore the prestige, whose cognitive interest becomes the leading motive that predominating over other motives, the socalled "human foibles". The difference between Sasha and Volodya was perceptible in those years only in the psychological experiment. What happened next in their lives? What about their scientific careers?

We didn't meet Volodya anymore during our longitudinal study, as he works abroad. It appears that he has started a business and become engaged in trade. We had our regular meeting with Sasha, now a leading scientist, in spring 2002. He was modest as usual, and willingly came to my institute for the experiment. He worked composedly in the experiment. The results were identical with the previous ones. The conversations with him showed that his values remained the same.

But how justified was our prognosis about the creative potential and its realization in professional activity? 10 years after finishing his postgraduate studies Sasha L. published a book on the topic of his dissertation. We managed to obtain the book review. Here is the small extract: "Many books have been written on theoretical physics. And there is a generally acknowledged example of such literature. It is the course of Landau and Lifshitz. It is not the point that the course contains 10 thick volumes - and it seems improbable that it was written by 2-3 authors. And it is not even the point that the course covers all of theoretical physics - such universal experts in all of theoretical physics cannot be found in the world any more. The reason that makes us admire this marvelous achievement is in the stunning beauty of the writing. When the author started to compose his book a chapter on this topic was missing in the course of Landau and Lifshitz but now it has been added. And however blasphemous it may sound, if we compare the chapter with the other 
parts, it stands up to the challenge... The author has written the book that no research in this field can get along without".

When finalizing our experiment in 2003 Sasha said: "I have told you the truth about myself, but not the whole truth". I hesitated to ask what he meant. It turned out that Sasha L. was the first in this class who became the corresponding member of the Russian Academy of Sciences.

The staff of the institute where he worked (one of the most elite institutes of the Russian Academy of Sciences) decided he should be elected its director. By the way, I asked him before that event if he was the head of a laboratory, but his answer was negative: all the scientists of the institute were simply research fellows.

But while Sasha L. with his creative level has become the corresponding member of the Russian Academy of Sciences, another creative personality, R.B., has not defended even a PhD. He is exploited in one of the funds, which needs his "ingenious brains" of an expert. He is absorbed in his work, which interests him, and he has got no other concerns. In other cases of tracking curriculi vitae and scientific achievements of our subjects the prognosis we made at the start has also been proved.

In one of our longitudinal studies we were able to predict the possibilities of growth for cognitive self-activity with the changes in the social situation of development during school age, and in the research given we have found out that the results obtained in the experiment were not only confirmed by the professional activity of our subjects, but the nature and the level of their professional achievements coincide with the style of their work in the experiment. It became very clear in the case of one of our most striking heurists H.I.: the regularities in his scientific field correspond with the type of regularities that he derived during the experiment.

The leading functions of the scientific creativity are the discovery of new laws, the formulation of new problems and the development of theories, so the analysis made from our perspective appears to be quite justified. The same view on the artistic creativity looks less obvious, as far as the opposition of artistic and scientific creativity has become traditional in psychology. The roots of this opposition lay in the differing nature of their final products. In the theoretical form of the product of the scientific activity - in the abstract construct - the rationale of its generative process is exposed. At the same time, it is somewhat of a transitional nature and 
needs additional procedures of practical realization. But the art forms its object before the final stage. It is not aware of the special procedures of "implementation into life". That is why the generative rationale (the act of the artistic vision, the grasp of meaning) has been already concealed in the product itself (Ivanov, 1977). Along with that the whole problem of creativity is especially acute in art as in the condensed expression of the creative aspect of human activity. It is in art that the professional success is foremost the creative one, and notably to a far greater degree than in any other realm of human activity. It is creativity that distinguishes a high-qualified craftsman and an artist. The main difficulty of the problem of creativity has been articulated by V.P. Ivanov: "The theoretical interpretation of the origins of the artistic activity, and, incidentally, the creativity in general", he writes, "has always been and remains the incredibly difficult task as it runs into the 'potential of unexpected' right at the point where it is intent to establish a law" (Ibid., p. 209).

But it is the phenomenon of the unexpected, 'not predetermined' that characterizes the higher forms of creativity in our understanding. It is the development of activity at one's own initiative that ensures the move into the realm that has not been determined. This gave us the right to include the analysis of artistic creativity in the context of our research. Consequently, the described above levels can be differentiated on the principle of mastery (stimulus-productive level) and art (heuristic and creative levels) as the further development of activity.

The experimental group consisted of students of the Gnesiny Institute and School, of the Moscow State Conservatoire, students of music schools in Riga and Moscow and professional musicians - approximately 400 subjects. The following examples show how creative abilities appear in musical activity of students high ability, general and special.

So, the subject T.O. belongs to the stimulus-productive level of cognitive self-activity. The elements of the main technique of her work in the Creative Field were demonstrated yet in the training experiment. Her cognitive activity did not go beyond the scope of the formulated task: each time she was stimulated by the presentation of a new task and exhausted her creative potential after finding the solution.

By the time T.O. left school she had already accomplished much in her professional field. It is the impeccable technique resulting from the daily practice and the quite mature professionalism that enabled her to 
perform in big theatres and halls. For better understanding of the specifics of the T.O. musical achievement her teacher's words can be quoted: "She has got an excellent ear for music. All the musical characteristics are excellent. She grasps everything easily and holds it firmly. She has got a fine technique. But along with that, the emotional side of performance suffers, she needs hints. She is predisposed to virtuosity, but when she plays Bach and Debussy she requires a hint at interpretation. She does not understand them on her own, but she is astonishingly diligent!" This reference coincides with the opinion of the teacher of musical literature: "She has not got her own judgments, though she is a good thinker". So, T.O. used to grasp everything quickly and held it firmly, she corrected her mistakes at once, when they were pointed out to her, i.e. she carried out all the tasks that had been given to her by her teachers. She was able to feel deeply the compositions that she was playing, but she needed to be directed. She easily succeeded in various virtuosic pieces but when the deep interpretation of the subject was needed she needed more hints. T.O. can fully demonstrate her musical ability when the tasks are clearly set, in this case she achieves astonishing results. Her school was proud of T.O. as its "celebrity" (she was the All-Union competition winner!), but some of the teachers pitied her: "Poor girl. She works so hard, that her mind is narrowed. She has not got a sparkle!" All the teachers agree that T.O. is nervous, she painfully takes critique and resents any critical remarks. She always strives to be the first in everything; she worries about her marks. And lastly, the opinions of most of the teachers coincided: "T.O. is exceptionally gifted and extremely hardworking. Maybe this is what we call talent?"

Another student of the same school, D.N., was also a splendid professional, though we consider her to belong to the stimulus-productive level too. She was exclusively musical, emotional, and felt fine on the stage. Her hands were not excellent, but she easily accommodated herself to the instrument: "with her little hands she easily copes with everything! She is very diligent and works a lot. She is sensitive, feels everything very subtly... Deals with the instrument easily... But her intellect works only for the 'task', and notably, just enough for the task and not more".

The subject K.D. was an excellent representative of the heuristic level of cognitive self-activity. He astonishingly quickly picked up the new activity, and he solved the first task of the main experiment just in $50 \mathrm{sec}-$ 
onds. While solving the second task he already found one of the highest regularities that had been hidden in the experimental material. During the experiment he uncovered lots of new methods of solution. However, the subject viewed his heuristics only as the means of improvement of the imposed activity. Neither hidden hints no direct questions could lead him to a theoretical generalization, to the explanation of the results of the performed analysis of his activity. The way this subject behaved in the experiment obviously showed that he belonged to the heuristic level of cognitive self-activity.

Let us turn now to the analysis of his professional mastery. K.D. was the pride of his school. "He is more than just gifted - he is talented! Everything comes naturally to him. He has got a phenomenal lightness and brilliance in everything! He is very sensitive. He has got lots of interests, so he is a delightful interlocutor. He succeeds both in lyrical, warm compositions, which suit his character, and in pieces that can be played with sparkle and boyish ardor, where he shows his special, truly inexhaustible ingenuity". K.D. is individualistic in performance: he shows sincerity, plasticity, poetic sentiment, warmness and spontaneity. He accepts the remarks, but along with that he manifests some independency. As one of his teachers remarked: "I give him one thing, but receive a different one, transformed." But yet one "can not really call him a substantial, profound musician", those pieces, which required a special depth of interpretation, did not enthrall him and did not come into his repertoire. Here is the opinion of his school teachers for non-music subjects: "He could as well be a wonderful chemist or mathematician". Our prediction was also verified: 10 years after the experiment K.D. became an inventor of cuttingedge musical equipment.

There were 2 students (M.Ch. and L.L.) who could be classified as representatives of the creative level of self-activity. The nature of their activity during the experiment and their musical activity significantly differed from the above mentioned.

All the teachers were unanimous: L.L. had magnificent musical potentialities, she possessed "divine" hands, absolute hearing and a lot more that makes up the perfect musical apparatus. But how did she use this technical apparatus? Others characterized L.L. primarily as a talented musician, a subtle interpreter. She was very well-read and knowledgeable. She had a brilliant intellect that helped her to analyze a music piece 
music, especially at the initial stage of work with the composition; she had a very deep, unique nature. Here is a memorable remark of the one of her schoolmates: "She likes to think a lot and knows how to do this..." Obviously, all these qualities of personality and intellect were expressed in her musical creative work: "Her performance differs from others: she does it in her own way, thoughtfully, unconventionally."

Thus, besides having wonderful musical potentialities the subject L.L. was also highly intelligent, was a self-starter in her professional sphere. Though she was only 18 , she already had "her own style" in music, which made her not just a performer, but a creator.

The subject M.Ch. announced as early as in the training experiment: "There might be some regularity in here". She obstinately looked for it and finally, at the end of the test, she was rewarded with her first big "discovery". She successfully used this uncovered regularity in deriving the highest hidden heuristics in the main experiments. Along with that it is worth noting that all the heuristics found by her were exceptionally substantial and sensible, she made very deep generalizations, based on the subtle and detailed analysis of the situation, as well as the truly inexhaustible thirst for search, for deeper understanding of the material.

Teachers spoke of M.Ch. as a person who showed specific features of her musical abilities underlying her exceptional giftedness as a performer despite some lacking physiological qualities. M.Ch. was one of the brightest talents of the school. According to her teachers, she deeply understands the style of musical compositions, so they could talk to her about the subtleties at once. M.Ch. was characterized by the craving to comprehend everything without missing a slightest thing. She read a lot, collected rare books, records, was keen on painting, poetry and kept abreast of all musical novelties. No wonder that M.Ch. used her knowledge of different fields of art while working on the piece. She had an astonishing depth and subtlety of the intellect. Despite the defective morphology of her hands ("stiff hands"!) she always played very colorfully and succeeded not only with the help of her technique, virtuosity, but with her thoughtful, deep interpretation. She understood everything very well and thoroughly thought over the compositions. Her teacher believed that M.Ch. "might become a very interesting, original chamber musician or, which is much more congenial to her, an outstanding musi- 
cal theorist." I witnessed that other teachers came to school on the day of her exams only to listen to her performance, though they were on medical leave at the moment: "It is always 'her own' music."

She failed her entrance exam in the conservatoire, which shocked the whole school. She was given 'poor' so she could not be allowed to take the examinations in other, non-musical subjects, as she had a good chance to pass them with flying colours. The selection committee did not like the morphology of her hands. The teachers were afraid that M.Ch. would commit a suicide: "She can not live without music". In this situation the school management asked psychologists for help. I explained to the girl the gist of the experiment in which she had participated some time before, the objectivity of its results, which showed her potentials, and I advised her to enter the theoretical department of the conservatoire, as her talent for theoretical reasoning was quite rare.

While M.Ch. was reading for the exam, she came up with some interesting thoughts about the "golden ratio" of sonatinas. She couldn't give it much thought at the moment because of lack of time, but then she remembered the words of the psychologist that scientists "walk past the discoveries when discarding the unimportant facts". She wrote a paper on the topic and presented it to the selection committee. Result: she was admitted to the conservatoire. I remember this day because of the wonderful bunch of roses from some greenhouse near Moscow which M.Ch. gave me when she came to my place. I never such roses either before or after that day.

Half a year after M.Ch. entered the conservatoire, the school received a letter of gratitude from the conservatoire administration for producing unique talents, and 12 years later they discussed her post-doctoral dissertation there.

Some years ago Marina called me from Holland. She received a Humboldt Research Award and lives in Europe now. She is presently a member of the Russian Composers' Association and the German Writers' Association. She has published several books of poems. Marina complained that Germans did not believe her that a psychologist predicted her future when she was still at school.

This spring Marina sent me her article for the Russian book Specifics of Dionisian Worldview of A.N. Skrabin. It contains a deepest musical and philosophical analysis of his creative work. Just before the publication of 
this article she informed me that she was preparing to publish her first novel. All these years Marina's gratefulness has filled my heart with joy as the recognition of power and benefits of psychological science.

\section{References}

Bogoyavlenskaya, D.B. (2002). Psikhologiya tvorcheskih sposobnostej [Psychology of Creative Abilities]. Moscow: Academia.

Bogoyavlenskaya, D.B. (2008). Two Paradigms - Two Vectors of Creating the New. In Psychology in Russia. State of the Art. Moscow: MSU.

Galton, F. (1865). Hereditary Talent and Character. MacMillan's Magazin, XII.

Ivanov, V.P. (1977). Chelovecheskaya Deyatelnost: Poznanie - Iskusstvo [Human Activity: Cognition - Art]. Kiev: Naukova Dumka. 